\title{
Contact Allergy to Nickel: Still \#1 After All These Years
}

\author{
John Moon, MS; Margo Reeder, MD; Amber Reck Atwater, MD
}

\section{PRACTICE POINTS}

- Nickel is the most common cause of contact allergy worldwide. It is ubiquitous in our daily environment, making avoidance challenging.

- Nickel allergic contact dermatitis typically presents in a localized distribution but also can present as systemic contact dermatitis.

- Nickel regulation has been adopted in Europe, but similar legislation does not exist in the United States.

Nickel is ubiquitous in our daily environment and remains the most common cause of contact allergy worldwide. Regulation of nickel release exists in Europe but unfortunately continues to be absent in the United States. Nickel contact allergy most often is associated with earrings and other jewelry; however, novel exposures to nickel through diet and electronic devices and other materials also occur. Once diagnosed, allergen avoidance is key for improvement of symptoms.

Cutis. 2021;107:12-15.

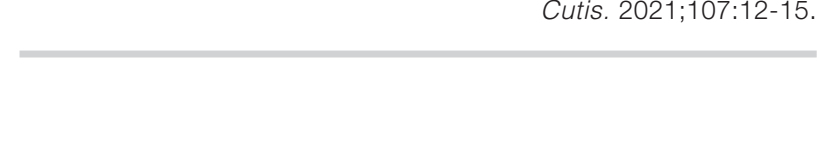

N ickel is unrivaled as the most common cause of contact allergy worldwide. ${ }^{1}$ Nickel is commonly used as a hardening agent in metal products, and complete avoidance is challenging due to numerous potential exposures (eg, direct contact, airborne, dietary, medical implantation). Allergic contact dermatitis to nickel (Ni-ACD) can lead to decreased quality of life, inability to work, and considerable health care expenses. ${ }^{1}$
Here, we review the epidemiology of nickel allergy, regulation of nickel in the United States and Europe, common clinical presentations, and pearls on avoidance.

\section{Epidemiology}

Nickel continues to be the most common cause of contact allergy worldwide. Data from the 2015-2016 North American Contact Dermatitis Group patch test cycle $(\mathrm{N}=5597)$ showed nickel sulfate to be positive in $17.5 \%$ of patients patch tested to nickel. ${ }^{2}$ The prevalence of nickel allergy has been relatively stable in North America since 2005 (Figure 1). Although Ni-ACD historically was identified as an occupational disease of the hands in male nickel platers, the epidemiology of nickel allergy has shifted. ${ }^{1}$ Today, most cases are nonoccupational and affect women more often than men, ${ }^{3}$ in part due to improved industrial hygiene, pervasive incorporation of nickel in consumer items, and differences in cultural practices such as piercings. ${ }^{1,3}$ Piercings in particular have been implicated as important sources of nickel exposure, as this practice disrupts normal skin barrier function and is a potentially sensitizing event. Multiple studies including a large-scale epidemiologic analysis from 2017 have found piercings to be associated with an increased frequency of $\mathrm{Ni}-\mathrm{ACD}$ ( $24.4 \%$ with piercing vs $9.6 \%$ without piercing). Interestingly, the degree of nickel sensitivity also was found to increase with the number of piercings ( $14.3 \%$ with 1 piercing vs $34.0 \%$ with $\geq 5$ piercings). ${ }^{4}$

\section{Regulation}

Nickel content has been regulated in parts of the European Union (EU) since the 1990s, but regulation in the

Mr. Moon and Dr. Reeder are from the Department of Dermatology, University of Wisconsin School of Medicine and Public Health, Madison.

Dr. Atwater is from the Department of Dermatology, Duke University School of Medicine, Durham, North Carolina.

Mr. Moon reports no conflict of interest. Dr. Reeder is Director of the ACDS Contact Allergen Management Program. Dr. Atwater is President of the American Contact Dermatitis Society (ACDS).

Correspondence: Margo Reeder, MD, 1 South Park St, 7th Floor, Madison, WI 53715 (mreeder@dermatology.wisc.edu).

doi:10.12788/cutis.0156 


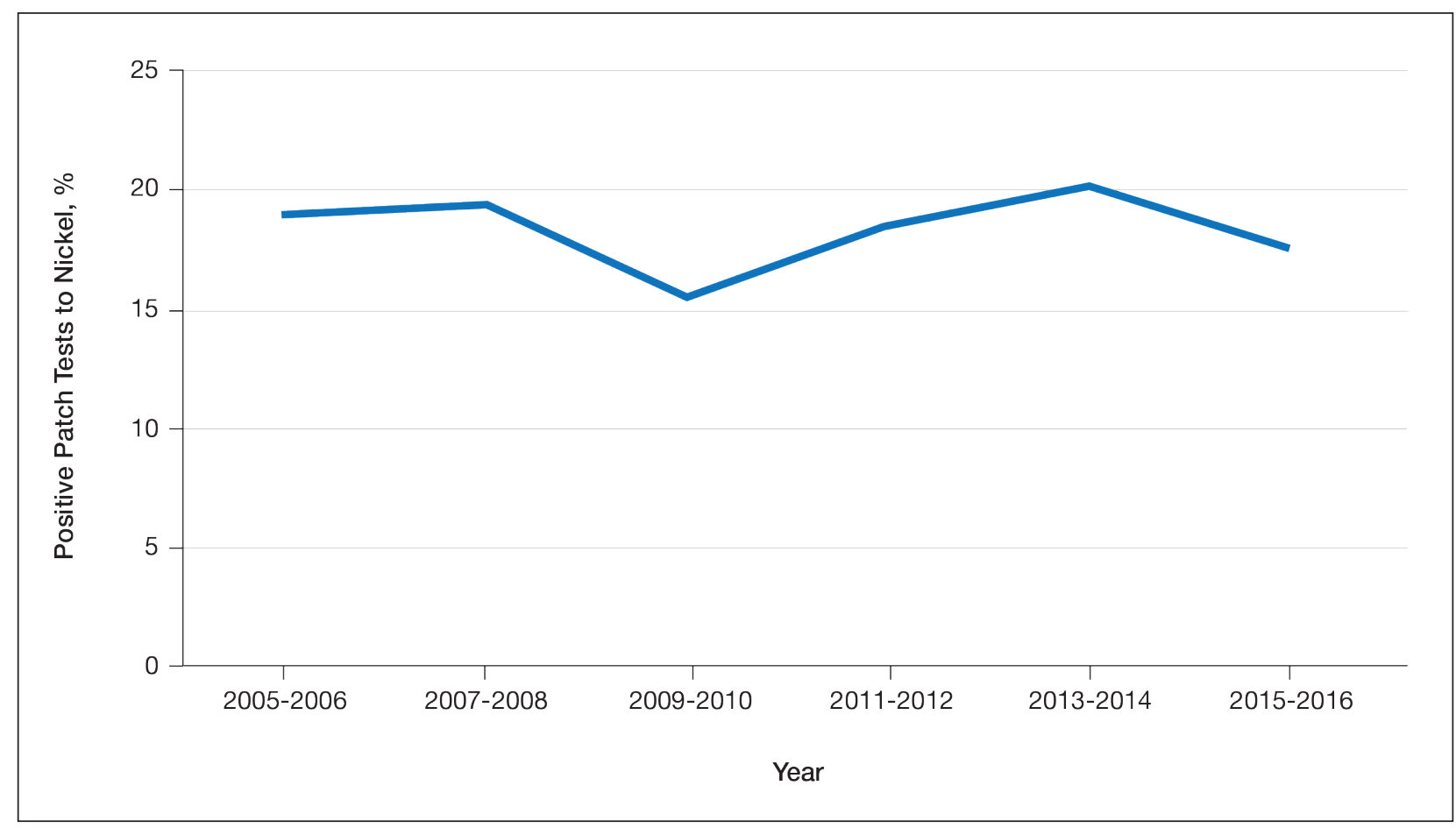

FIGURE 1. Positive patch tests to nickel from 2005 to 2016 from the North American Contact Dermatitis Group. ${ }^{2}$

United States is lacking. In an attempt to reduce the prevalence of nickel allergy, the EU limits the level of nickel release from consumer items intended to be in direct and prolonged contact with the skin. These limits were first introduced in Denmark in 1990, followed closely by the EU Nickel Directive in 1994, which has resulted in consistent patterns of decreasing prevalence of Ni-ACD in multiple European countries. ${ }^{5}$ Notably, a Danish study comparing the prevalence of sensitization between girls with ears pierced before vs after implementation of nickel regulation found a decrease in prevalence from $17.1 \%$ to $3.9 \% .{ }^{6}$ Additionally, this initiative has greatly reduced the economic burden of nickel dermatitis. It is estimated that Denmark alone has saved US \$2 billion over a 20-year period in both direct and indirect health care costs. ${ }^{7}$

However, a policy is only effective if it is enforced, and it has been reported in the EU that $8 \%$ to $32 \%$ of tested jewelry exceeds the limit placed on nickel release, with imported jewelry being especially problematic. ${ }^{5}$ Also of interest, the 1 and 2 euro coins are known to release more nickel than pure nickel itself, releasing 240 to 320 times more than is allowed under the EU Nickel Directive (Figure 2). ${ }^{8}$ Although coins are not explicitly mentioned as items having prolonged contact with the skin, they can and do exacerbate allergic contact dermatitis of the hands, especially in occupational groups such as cashiers. ${ }^{9}$ Unsurprisingly, during the discussions to determine the composition of coins prior to the mass adoption of the euro in the EU in 2002, dermatologists and nickel industry experts remained divided in their recommendations. ${ }^{10}$ However, the EU regulation is considered a public health success overall, and the trends of $\mathrm{Ni}-\mathrm{ACD}$ and economic burden are opposite of the United States, where legislation has yet to be adopted.

\section{Patch Testing to Nickel}

In North America, the 2 available patch test systems are the chamber method and the Thin-layer Rapid Use Epicutaneous (T.R.U.E.) test (SmartPractice). In the T.R.U.E. test, nickel sulfate is used to formulate the patch at $200 \mu \mathrm{g} / \mathrm{cm}^{2}$ using hydroxypropyl cellulose as the gel vehicle. In the chamber method, nickel sulfate is used on either an aluminum or plastic chamber, most commonly at concentrations of $2.5 \%$ or $5 \%$ in petrolatum. Nickel sulfate $2.5 \%$ is most frequently used in US-based patch test clinics. A 2018 study $(\mathrm{N}=205)$ comparing the sensitivities of the $2.5 \%$ and $5 \%$ concentrations of nickel found $5 \%$ to be more sensitive; $31 \%$ of the cohort tested positive at $5 \%$ but only $20 \%$ at $2.5 \%$, suggesting the $5 \%$ formulation is superior at detecting nickel allergy. ${ }^{11}$

Similar to other metals, nickel may react later than other allergens. A 2019 analysis of the prevalence of new patch test reactions on day 7 showed that $17 \%$ of 607 patients were negative on day 3 but were positive on day 7 , further emphasizing the importance of a properly timed delayed reading. ${ }^{12}$

\section{Clinical Presentation}

Localized-The classic presentation of Ni-ACD is a scaly erythematous dermatitis in a typical distribution 


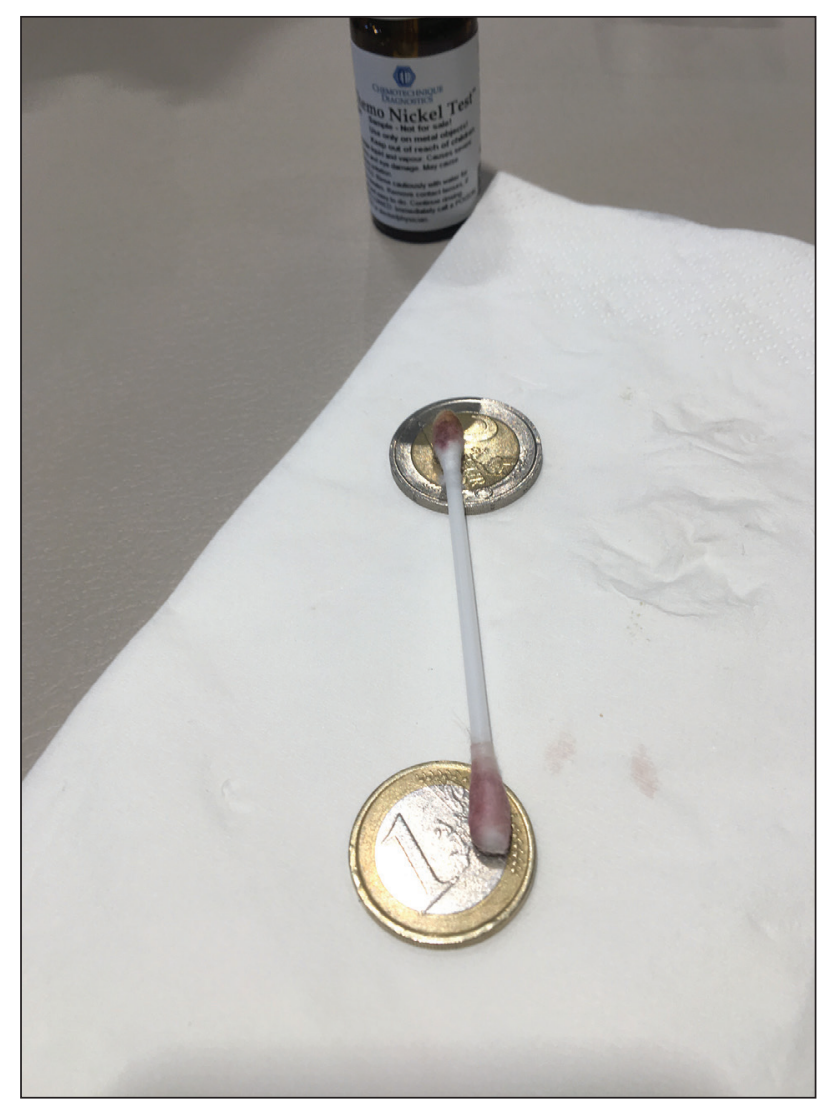

FIGURE 2. A dimethylglyoxime test demonstrated release of nickel from 1 and 2 euro coins.

(eg, earlobes [earrings], wrists [watch], periumbilical [belt]). These scenarios usually can be diagnosed by the astute clinician without patch testing; however, the source of exposure may be less obvious if the nickel-releasing item has intermittent contact with the skin (eg, coins in the pocket, furniture hardware, personal grooming devices).$^{13}$ Other reported exposures include facial dermatitis from mobile phones, dermatitis of the ulnar hands from laptop use, and hand dermatitis from gaming controllers, ${ }^{14-16}$ perhaps another reason for some to unplug.

Systemic-Sensitized individuals also may present with systemic contact dermatitis after airborne, oral, mucosal, or intravenous exposure. Presentations vary but have been reported to manifest as flare-up reactions in previously affected areas, pompholyx, diffuse dermatitis, flexural dermatitis, and baboon syndrome. ${ }^{17}$ Although it is unknown if airborne exposure alone is sufficient for sensitization, cases have been reported in occupational settings. ${ }^{18}$ One report described a man presenting with widespread dermatitis involving the extremities, chest, and genital area after his first day working at an electroplating plant. ${ }^{19}$

Systemic contact dermatitis from foods high in nickel (eg, chocolate, sunflower seeds, whole-grain flour, dried beans) and occasionally nonfood items (eg, coins) also has occurred. The so-called Easter egg hunt dermatitis has been described in children with Ni-ACD after candy ingestion. ${ }^{20}$ Another case described an 8-year-old girl and budding illusionist with severe diffuse dermatitis; a thorough history revealed the dermatitis began after she ingested a coin while performing a magic trick. ${ }^{21}$

Cases of nickel systemic contact dermatitis have been reported following medical device implantation, including reactions to cardiac devices, orthopedic implants, neurosurgery materials, and others. ${ }^{22}$ In addition, both intraoral and extraoral manifestations following application of orthodontic materials and dental implants have been reported. ${ }^{23,24}$ Although nickelcontaining medical devices generally are well tolerated even in nickel-sensitive individuals, the development of systemic Ni-ACD has at times required device or hardware removal. ${ }^{22,23}$

\section{After the Patch Test: Avoidance of Nickel}

Counseling patients on nickel avoidance is critical to clinical improvement. Common nickel-containing items include jewelry, metal on clothing (eg, zippers, clasps, grommets), belt buckles, watches, glasses, furniture, coins, and keys. Numerous personal care products may also contain nickel, including nail clippers, eyelash curlers, tweezers, mascara tubes, and razors. ${ }^{25,26}$ Patients should be made aware that nickel-free alternatives are available for the majority of these products. Internetbased tips such as painting nail polish on products or iron-on patches tend to be of limited use in our experience. Patients may consider purchasing a nickel spot test to detect nickel in their environment; the dimethylglyoxime nickel spot test is inexpensive, rapid, and easy-to-use. To use the test, a small amount of the chemical is rubbed on the metal item using a cotton swab; a pink color indicates nickel release. Patients can be reassured that dimethylglyoxime does not harm jewelry.

Some general advice for patients regarding jewelry, the most common source of nickel exposure, is to only wear jewelry that is made from metals such as surgicalgrade stainless steel, pure sterling silver, or platinum. If yellow gold is the preferred metal, it is prudent to be aware that lower karat items could potentially contain nickel. White gold should be avoided, as it often contains nickel to contribute to its color. Finally, gold-plated jewelry should be avoided, as the plating can wear off and expose a possibly nickel-containing base.

A low-nickel diet may be of benefit in select patients. A meta-analysis assessing systemic contact dermatitis from nickel ingestion found that $1 \%$ of nickel-sensitive individuals may be expected to react to nickel found in a normal diet. ${ }^{27}$ However, as with any diet, adherence can be difficult. Thankfully, Mislankar and Zirwas ${ }^{28}$ have developed a simple point-based system to help increase compliance. Additionally, a free mobile application is now available; Nickel Navigator (http://rebelytics .ca/nickelnavigator.html) can be used to track daily 
nickel intake and may be especially convenient for our more tech-savvy patients. In conjunction with a low-nickel diet, some authors also recommend eating meals high in vitamin $C$ or supplementation with vitamin $\mathrm{C}$, as co-ingestion has been shown to reduce nickel absorption. ${ }^{29}$

\section{Final Interpretation}

Nickel allergy remains common, found in up to $17.5 \%$ of patch tested patients. Despite regulation in the EU, nickel continues to have high prevalence of positive patch test reactions around the world. Nickel is not only found in jewelry and belt buckles but also in personal care products, electronics, and food. Allergen avoidance is key and requires knowledge of common items containing nickel and a low nickel diet for select patients.

\section{REFERENCES}

1. Ahlström MG, Thyssen JP, Wennervaldt $M$, et al. Nickel allergy and allergic contact dermatitis: a clinical review of immunology, epidemiology, exposure, and treatment. Contact Dermatitis. 2019;81:227-241.

2. DeKoven JG, Warshaw EM, Zug KA, et al. North American Contact Dermatitis Group Patch Test Results: 2015-2016. Dermatitis. 2018;29:297-309.

3. Thyssen JP, Menné T. Metal allergy-a review on exposures, penetration, genetics, prevalence, and clinical implications. Chem Res Toxicol. 2010;23:309-318.

4. Warshaw EM, Aschenbeck KA, DeKoven JG, et al. Piercing and metal sensitivity: extended analysis of the North American Contact Dermatitis Group data, 2007-2014. Dermatitis. 2017;28:333-341.

5. Ahlström MG, Thyssen JP, Menné T, et al. Prevalence of nickel allergy in Europe following the EU Nickel Directive-a review. Contact Dermatitis. 2017;77:193-200.

6. Jensen CS, Lisby S, Baadsgaard $O$, et al. Decrease in nickel sensitization in a Danish schoolgirl population with ears pierced after implementation of a nickel-exposure regulation. $\mathrm{Br} J$ Dermatol. 2002; 146:636-642.

7. Serup-Hansen N, Gudum A, Sørensen MM. Valuation of Chemical Related Health Impacts. Danish Environmental Protection Agency. Published 2004. Accessed December 14, 2020. https://www2.mst.dk /udgiv/publications/2004/87-7614-295-7/pdf/87-7614-296-5.pdf

8. Nestle FO, Speidel H, Speidel MO. Metallurgy: high nickel release from 1- and 2-euro coins. Nature. 2002;419:132.

9. Kanerva L, Estlander T, Jolanki R. Bank clerk's occupational allergic nickel and cobalt contact dermatitis from coins. Contact Dermatitis. 1998;38:217-218.
10. Aberer W. Platitudes in allergy-based on the example of the euro. Contact Dermatitis. 2001;45:254-255.

11. Goldminz AM, Scheinman PL. Comparison of nickel sulfate $2.5 \%$ and nickel sulfate $5 \%$ for detecting nickel contact allergy. Dermatitis. 2018;29:321-323.

12. van Amerongen CCA, Ofenloch R, Dittmar D, et al. New positive patch test reactions on day 7 -the additional value of the day 7 patch test reading. Contact Dermatitis. 2019;81:280-287.

13. Silverberg NB, Pelletier JL, Jacob SE, et al; Section of Dermatology, Section on Allergy and Immunology. Nickel allergic contact dermatitis: identification, treatment, and prevention. Pediatrics. 2020;145:E20200628.

14. Aquino M, Mucci T, Chong M, et al. Mobile phones: potential sources of nickel and cobalt exposure for metal allergic patients. Pediatr Allergy Immunol Pulmonol. 2013;26:181-186.

15. Jensen P, Jellesen MS, Møller P, et al. Nickel allergy and dermatitis following use of a laptop computer. I Am Acad Dermatol. 2012;67:E170-E171.

16. Jacob SE. Xbox-a source of nickel exposure in children. Pediatr Dermatol. 2014;31:115-116.

17. Menné T, Veien NK. Systemic contact dermatitis. In: Rycroft RJG, Menné T, Frosch PJ, et al, eds. Textbook of Contact Dermatitis. Springer; 2001:355-366.

18. Mann E, Ranft U, Eberwein G, et al. Does airborne nickel exposure induce nickel sensitization? Contact Dermatitis. 2010;62:355-362.

19. Candura SM, Locatelli C, Butera R, et al. Widespread nickel dermatitis from inhalation. Contact Dermatitis. 2001;45:174-175.

20. Jacob SE, Hamann D, Goldenberg A, et al. Easter egg hunt dermatitis: systemic allergic contact dermatitis associated with chocolate ingestion. Pediatr Dermatol. 2015;32:231-233.

21. Mahdi G, Israel DM, Hassall E. Nickel dermatitis and associated gastritis after coin ingestion. J Pediatr Gastroenterol Nutr. 1996;23:74-76.

22. Basko-Plluska JL, Thyssen JP, Schalock PC. Cutaneous and systemic hypersensitivity reactions to metallic implants. Dermatitis. 2011;22:65-79.

23. Schultz JC, Connelly E, Glesne L, et al. Cutaneous and oral eruption from oral exposure to nickel in dental braces. Dermatitis. 2004;15:154-157.

24. Pigatto PD, Brambilla L, Ferrucci S, et al. Systemic allergic contact dermatitis associated with allergy to intraoral metals. Dermatol Online J. 2014;20:13030/qt74632201.

25. Brandrup F. Nickel eyelid dermatitis from an eyelash curler. Contact Dermatitis. 1991;25:77.

26. Walsh G, Wilkinson SM. Materials and allergens within spectacle frames: a review. Contact Dermatitis. 2006;55:130-139.

27. Bergman D, Goldenberg A, Rundle C, et al. Low nickel diet: a patientcentered review [published May 24, 2016]. J Clin Exp Dermatol Res. doi:10.4172/2155-9554.1000355

28. Mislankar M, Zirwas MJ. Low-nickel diet scoring system for systemic nickel allergy. Dermatitis. 2013;24:190-195.

29. Zirwas MJ, Molenda MA. Dietary nickel as a cause of systemic contact dermatitis. J Clin Aesthet Dermatol. 2009;2:39-43. 